\title{
How Online Privacy Systems Assure More Customer Satisfaction and Trust?
}

\author{
Chia Thian Sheung ${ }^{1^{*}}$ and Rashad Yazdanifard ${ }^{2}$ \\ ${ }^{1}$ SNHU Department, Help College of Arts and Technology, Fraser Business Park, Kuala Lumpur, Malaysia \\ ${ }^{2}$ Faculty of Management, Multimedia University, Cyberjaya, Malaysia
}

*Corresponding author: Chia Thian Sheung, SNHU Department, Help College of Arts and Technology, Fraser Business Park, Kuala Lumpur, Malaysia, Tel: +603-27882000; E-mail: hyroan@hotmail.com

Received date: March 11, 2014; Accepted date: December 01, 2014; Published date: December 10, 2014

Copyright: ( 2014 Sheung CT, et al. This is an open-access article distributed under the terms of the Creative Commons Attribution License, which permits unrestricted use, distribution, and reproduction in any medium, provided the original author and source are credited.

\begin{abstract}
The use of technology helps organizations to get closer to customers and to build an ongoing relationship with them. As the usage of Internet grows rapidly in recent years, especially in online shopping and payment via Internet, we can observe that there is a rising number of people concerning about online privacy. Users are increasingly concerned about their own privacy when they go online; this has been repeatedly shown in studies developed by researchers. Thus, the way of compiling consumer data profiles may play an important role in assuring consumer satisfaction and trust have been fully taken into account. Customers' perceived risk will be lower in electronic marketplace if they obtained a sufficient level of satisfaction as well as trust. Also, in a society having a high level of privacy awareness, the accessibility of privacy policies while navigating a website's page and the understanding of relevant contents in the policy have been focused and considered by organizations to improve their service quality in terms of online privacy system. The purpose of this paper is presented is to allow us a better understanding of the online privacy measurements and to evaluate the usability of online privacy policies. We also examine the four aspects of policies and how they can be improved in order to meet more user satisfaction and trust.
\end{abstract}

Keywords: Internet; Electronic commerce; Online privacy system; Online trust; Customer satisfaction

\section{Introduction}

"The rapid growth of online transactions in the service industry raise interesting in conducting research about the levels of satisfaction and loyalty in the online circumstance" [1]. How marketers assure more customer satisfaction and loyalty in online environment? Marketing strategies are key elements in improving customer purchase intentions; reliability, trustworthy, and responsiveness of web-based services are fundamental to address and should be developed in online stores. Regarding to the researcher's survey which had completed by Ahuja et al. [2], survey showed two samples of quantitative data, both are distinct groups involving students and non-students. Figure 1 below shows the major barriers and benefit to shop online, the most concern about shopping online in both samples was privacy and security, followed by customer service, lack of interaction, and high prices. This Figure 2 shows that online privacy and security have increasingly concerned by consumers when they go online. According to Pavlou [3], 'trust has long been regarded as catalyst for buyer-seller transactions that can provide high expectations for consumers of satisfying exchange relationships' (p.70). McKnight et al. [4] claim that trust allows consumers to overcome perceptions of uncertainly and risk which constituted as a fundamental element in influencing consumer behaviour. According to Kim et al. [5], "technological trust has been targeted primarily by improving the online privacy and security" (p.545). People may have a risky Internet purchase without trust. According to Gommans et al. [6] as cited in Reichheld, "e-loyalty is all about quality customer support, on-time delivery, compelling product presentations, convenient and reasonably priced shipping and handling, and clear and trustworthy privacy policies" (p.44). The Internet marketplace has proven a great place for marketing and advertising as well as has significant implications for privacy [7]. This study examines privacy measurement that can increase customer satisfaction and trust; presenting a comprehensive analysis of the different aspects of policies to deliver user needs, which consist of content, structure, navigate, and accessibility.

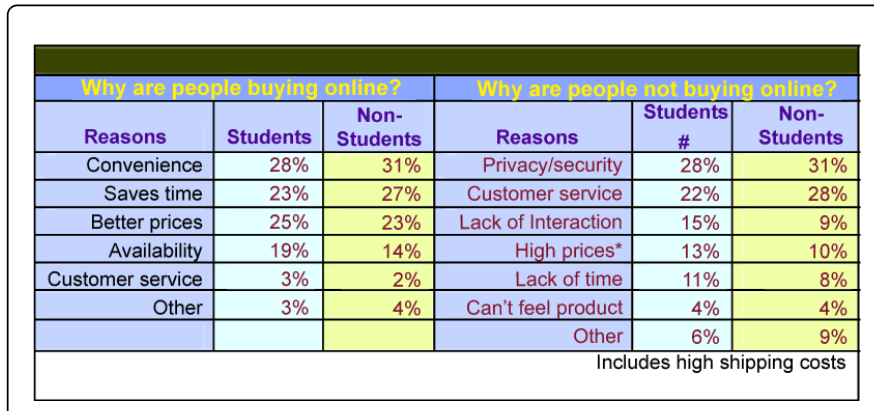

Figure 1: Motivating factors and barriers [2].

\section{Review of Privacy Measurement}

Based on the studies conducted by Buchanan et al. [8], two concepts of privacy concern are the Concern for Information Privacy (CFIP) and Internet Users Information Privacy Concern (IUIPC). According to Angst and Agarwal in [9] as cited in Smith, Milberg and Burke, concern for information privacy (CFIP) was developed and tested by Smith, Milberg, and Burke in 1996 to measure beliefs and attitudes towards individual privacy which related to the use of personal profiles information in online business setting. CFIP has been conceptualized and being divided into four distinct factors, error, collection, secondary use, and unauthorized access. Soon, research conducted by Stewart and Segars in 2002 claimed that CFIP needed to be re- 
evaluated and advancing in term of technology, practice, and research. Finally, Angst and Agarwal [9] mentioned that CFIP has been used in isolating and identifying the value of privacy assurances on Internet. Most recent, another privacy concern has been determined known as Internet Users Information Privacy Concerns (IUIPC).

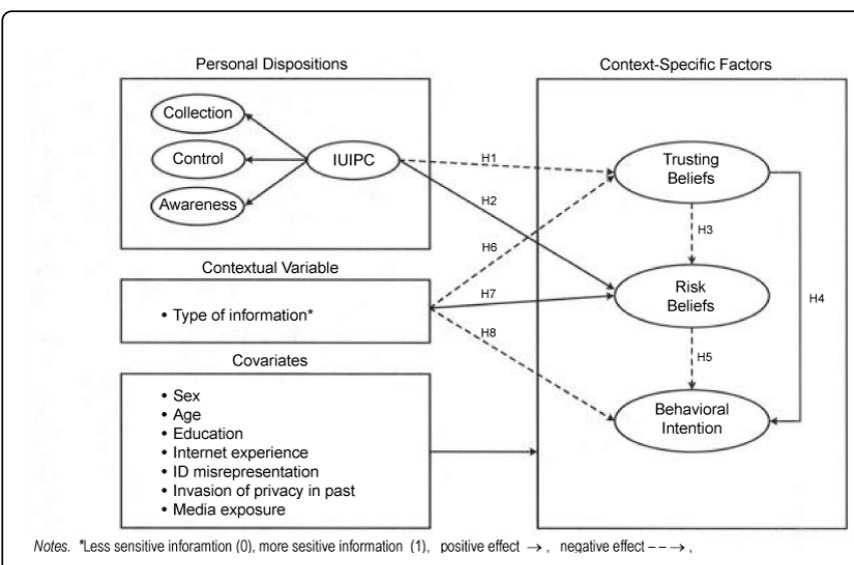

Figure 2: Proposed Model [10].

This model is differentiates from CFIP that determines various aspects of informational privacy: identify attitudes towards the collection of personal information, control over individual profiles; and awareness of privacy concerns. Figure 2 conducted by Malhotra et al. [10] shows the three aspects of IUIPC and the relationships between IUIPC, trusting beliefs, risk beliefs, and intention. IUIPC expected to be negatively relationship with trusting beliefs and positively relationship with risk beliefs.

\section{Collection}

The issue of data collection is the initial point of various information privacy concerns, either legal or illegal. Based on Malhotra et al. [10] stated that collection defined as the first dimension in IUIPC, "as the degree to which a person is concerned about the amount of individual-specific data possessed by others relative to the value of benefits received" (p.338). According to Li et al. [11], "consumers perceive certain types of requested information to be privacy invasive varies across the purpose of information collection" (p.438). Even information such as gender and age in context which is irrelevant to the transaction may increase users alert about potential privacy risks as well as trustworthiness of the vendor in the future. Hence, online companies "give their customers a certain level of control over the collection and use of their personal information" [12]. The collection is one of the parts of CFIP dimensions which is also being characterized to become one of the important factor in IUIPC model.

\section{Control}

Control is fundamental factor in describing the personal perceptions of privacy invasion ([13] as cited in Sheehan and Hoy). People nowadays are required to have the ability to control over their own personal profiles. Research shown in Malhotra et al. [10] as cited by Phelps et al. illustrated that the probability of people requested to have more flexible control over their personal data in order to limit unwanted advertisements has been occupied 84\% among others. Consumers tend to perceive information disclosure as less privacy invasion as they have more flexibility to control over their own personal information [13]. Control is the most important factors compare with collection and awareness of privacy practices that affecting privacy concerns among Internet users. Fair process will be deemed by individuals as they are given more flexibility to control over certain aspects of personal privacy submission in Internet [14]. Thus, Internet technologies have been given more flexible ways for consumers to control over their own personal information in a company's database.

\section{Awareness of privacy practices}

"Awareness is a passive dimension of information privacy and it refers to the degree to which a consumer is concerned about his/her awareness of organizational information privacy practices" ([10] as cited in Culnan, Foxman and Kilcoyne, p.339). According to Gurung et al. [15], higher level of awareness of privacy protections may decrease the risk perceptions of the users. Less privacy concerns together with more perceived control will be experienced by consumers when they are more knowledgeable about the privacy practices and available options for safeguarding their own information. Users are more likely to engage in risky activities such as online purchase, providing personal information, and banking over the Internet when they have higher level of awareness of privacy measures. It shows that Internet privacy awareness provides users with more sufficient confidence to participating in online transaction by mitigating their fears of their privacy concerns. With the increasing level of internet experience, users are more likely to be aware of protective measures and tend to positive relationship with more intention to transaction via online [15].

\section{Online Privacy Policies}

According to Jensen and Potts [16], "privacy policies are everywhere and are often the only source of information about a company's privacy practices" to determine whether they could meet the needs of users (p.472). Privacy policy has been posted in most of the websites to address issues that different from those users who are caring about. According to Bolchini et al. [17], privacy policy is a "comprehensive description of a website's practices on collecting, using and protecting customer information" (p.31). It determined what types of information should be collected, what purposes of using such information, how is information be stored, handled, and used, whether customers are permitted to access their personal information, and also how to settle privacy-related disputes in the website. Recently, privacy policies published on websites are increasingly complex and usually long which are difficult to understand by users. Research discovered that many online privacy policies are lacking of clarity and require higher reading skill level compare with the Internet population's average literacy level [17]. There are four aspects of privacy policies elaborating the current website situation, which covered content, structure, navigation, and accessibility. The researcher also developed how current aspects needed to be improved in enabling Internet users to have better navigate and understand website privacy policies as well as increase users' privacy awareness.

\section{Content}

All privacy policies build on the assumption that visiting the site implies user's consent to the site's policy, whether they read it or not [16]. Unfortunately, users usually found difficulty to understand the language used in the privacy policies; users may also fall difficulty to 
Page 3 of 4

understand the benefits and potential threats entailed by the submission of their personal information. Recent studies demonstrated that website privacy policies are often conflicting and ambiguous users from understanding how their personal information will actually be treated [17].

\section{Structure}

Different websites have different ways in presenting their privacy practices to users. Bolchini, et al. [17] has analysed few policies used by three large companies, which include Barnes \& Noble, Amazon and buy.com:

"For example, some policies (see www.bn.com) firstly explain what information they collect, and then how the organization will use and share this information. Other policies (see www.buy.com) tell where on the site they will collect user information and then focus on the strategy and technology used to protect that information. Other sites (see wWw.amazon.com) organize their policy's content with a list of frequently asked questions (FAQs), abruptly varying from very general issues (such as the kind of information collected) to technical details (e.g. the use of cookies) in the attempt to promptly answer the recurrent issues raised by the website's customers" (p.32).

"Strategy chosen to organize the content of the privacy policy in most of the cases; structure presented the policy to users takes the shape of a long document with several section" [17]. Putting all information into one document may useful result in getting a general overview of the privacy practices in Internet, however, having such structure in policy text may found difficult to be contextualized into usage scenarios which users may concerned about the specific data rather than the general overview of privacy practices [17].

\section{Navigation}

According to Metzger [18], customer perceived trustworthiness of and revelation to commercial Websites will impacted from the navigation features. Studies conducted by Bolchini et al. [17] found that "privacy policy navigation is context-independent, wherever a user is navigating on the site; she can only access the entire privacy policy document" (p.32). Order of policy to whom the user is doing on the site is always the same. To reach such information, the user probably has to read a long and confusing document in another page which explaining some common terms of the privacy, how organization's effort in protecting consumer personal data, which presented users with significant barrier to retrieve such information that they are interested [17]. Thus, consumer will more likely to make decision blindly in order to proceed the site and how personal information being used by the site is uninformed [17].

\section{Accessibility}

Individual's purchasing decisions and trust against the Website may affected by accessibility of privacy information [18]. Poor accessibility of privacy policies may influence the privacy document difficulty to spot. Many privacy policies are designed as a recurrent pattern, or smaller font size at the bottom of the page. Even it is accessible from the site, it still not relevant or difficult to parse in particular web pages when attempting to retrieve certain information [17].

\section{Discussion}

Privacy measurement has been developed into two distinct concepts, which includes Concern for Information Privacy (CFIP) and Internet Users Information Privacy Concern (IUIPC) [19]. Both concepts are to measure attitudes and beliefs about individual information privacy related to the use of personal information in a business setting as well as to recognize multiple aspects of informational privacy: identify attitudes towards the collection of personal information, control over individual information; and awareness of privacy concerns of company gathering personal information. Both models have been focused to have more concern about customers' personal privacy. On the other hand, the study in the online privacy policies are divided into four main factors: Content, structure, navigation and accessibility. The study gives a brief idea to should how a current web design be improved to allow Internet users a better navigation and understanding of website privacy policies and increase in users' privacy awareness. Also, online privacy policies in Websites should be improved so that users can have a better understanding of websites' privacy practices by accessing the relevant information quickly and increase their privacy-awareness [20]. Websites can build the trust from end-users by specifying privacy policies in an easy to access, easy to understand way to satisfy users' specific privacy needs.

\section{Conclusion}

In line with many E-marketing researches concerning the factors which give consumer satisfactions in online purchasing experiences, this paper found that online privacy system have few dominant factors which influence consumer perceptions in online purchasing experiences. This paper tends to discuss the concepts of Internet Users Information Privacy Concerns (IUIPC) delivered to identify attitudes towards the collection of personal information, control over individual information; and awareness of privacy concerns of company gathering personal information. This concept aims to meet users' need and lead to customer satisfaction and trust in certain websites. On the other hand, there are also few aspects of online privacy policies such as content, structure, navigation, and accessibility which can be discussed. Pitfall in web design may give a vague navigation and understanding in the website privacy policies as aforementioned. Therefore, these factors should be carefully examined in order to gain customer trust and satisfaction.

\section{References}

1. Shankar V, Smith AK, Rangaswamy A (2003) Customer satisfaction and loyalty in online and offline environments, International journal of research in marketing, 20: 153-175.

2. Ahuja M, Gupta B, Raman P (2003) An empirical investigation of online consumer purchasing behaviour. Communications of the ACM 46: 145-151.

3. Pavlou PA (2003) Consumer acceptance of electronic commerce: Integrating trust and risk with the technology acceptance model. International Journal of Electronic Commerce 7: 69-103.

4. McKnight DH, KC (2002) The impact of initial consumer trust on intentions to transact with a website: A trust building model. Journal of Strategic Information System 11: 297-323.

5. Kim DJ, Ferrin DL, Rao HR (2007) A trust-based consumer decisionmaking model in electronic commerce: The role of trust, perceived risk, and their antecedents. Decision Support System 44: 544-564. 
Citation: Sheung CT, Yazdanifard R (2014) How Online Privacy Systems Assure More Customer Satisfaction and Trust?. Int J Econ Manag Sci 3: 209. doi:10.4172/2162-6359.1000209

Page 4 of 4

6. Gommans M, Krishnan KS, Scheffold KB (2001) From brand loyalty to eloyalty: A conceptual framework, Journal of Economic and Social Research 3: 43-58.

7. Brown M, Muchira R (2004) Investigating the relationship between internet privacy concerns and online purchase behaviour. Journal of Electronic Commerce Research 5: 62-70.

8. Buchanan T, Paine C, Joinson N, Reips U (2007) Development of measures of online privacy concern and protection for use on the Internet. Journal of the American Society for Information Science and Technology 58: 157-165.

9. Angst CM, Agarwal R (2009) Adoption of electronic health records in the presence of privacy concerns: The elaboration likelihood model and individual persuasion. MIS Quarterly 33: 339-370.

10. Malhotra NK., Kim SS, Agarwal J (2004) Internet users' information privacy concerns (IUIPC):The construct, the scale, and a causal model. Information Systems Research 15: 336-355.

11. Li H, Sarathy R, Xu H (2011) The role of affect and cognition on online consumers' decision to disclose personal information to unfamiliar online vendors. Decision Support Systems 51: 434-445.

12. Whitley EA (2009) Informational privacy, consent and the "control" of personal data. Information security technical report 14: 154-159.

13. $\mathrm{Xu} \mathrm{H} \mathrm{(2007)} \mathrm{The} \mathrm{effects} \mathrm{of} \mathrm{self-construal} \mathrm{and} \mathrm{perceived} \mathrm{control} \mathrm{on}$ privacy concerns. Twenty Eighth International Conference on Information Systems 1-14.
14. Zukowski T, Brown I (2007) Examining the influence of demographic factors on internet users' information privacy concerns, In Proceedings of the 2007 annual research conference of the South African institute of computer scientists and information technologists on IT research in developing countries. 197-204.

15. Gurung A, Luo X, Raja MK (2008) An Empirical Investigation on Customer's Privacy Perceptions, Trust and Security Awareness in Ecommerce Environment. Journal of Information Privacy \& Security 4: 42-63.

16. Jensen C, Potts C (2004) Privacy policies as decision-making tools: An evaluation of online privacy notices. In Proceedings of the SIGCHI conference on Human factors in computing systems 6: 471-478.

17. Bolchini D, He Q, Antón A I, Stufflebeam W (2004) I Need It Now: Improving website usability by contextualizing privacy policies. SpringerVerlag Berlin Heidelberg 31-44.

18. Metzger MJ (2006) Privacy, trust, and disclosure: Exploring barriers to electronic commerce. Journal of Computer-Mediated Communication 9.

19. Tsai JY, Egelman S, Cranor L, Acquisti A (2011) The effect of online privacy information on purchasing behaviour: An experimental study. Information Systems Research 22: 254-268.

20. Lee GG, Lin HF (2005) Customer perceptions of e-service quality in online shopping. International Journal of Retail \& Distribution Management 33: 161-176. 